\title{
MÁRMOLES PARA LA COLEGIATA DE OSUNA: LA NUEVA SOLERÍA Y OTRAS ACTUACIONES EN SU FÁBRICA ENTRE 1770 Y 1804
}

\author{
MARBLES FOR COLEGIATA DE OSUNA: NEW \\ FLOORING AND OTHER ACTIONS IN ITS \\ CHURCH BETWEEN 1770 AND 1804
}

\author{
Antonio Joaquín Santos Márquez \\ Universidad de Sevilla. España \\ anjo@us.es
}

\begin{abstract}
En este artículo se da a conocer todo el proceso histórico que aconteció en la colegiata de Osuna durante la colocación de la nueva solería del templo entre los años de 1770 y 1804.

Palabras clave: arte lapidario; Estepa; familia Blanco; solería; colegiata de Osuna.

This paper discloses the whole historical process of placing a new flooring at the colegiata de Osuna between 1770 and 1804.

Keywords: lapidary art; Estepa; Blanco family; flooring; colegiata de Osuna.
\end{abstract}

La colegiata de Osuna es una magnífica edificación renacentista que guarda un rico tesoro de arte mueble que ha merecido los más importantes elogios. Sin embargo, a pesar de esta riqueza artística, existen aún muchos silencios sobre su historia y los protagonistas que la convirtieron en uno de los templos más interesantes de la provincia de Sevilla. Por ello, toda aportación documental que esclarezca el desarrollo histórico-artístico de esta iglesia es bien recibida, como es el caso de la remodelación que aconteció en el templo en el último tercio del siglo XVIII que centra el argumento de nuestro artículo.

No puede extrañarnos que, en este periodo histórico de clara decadencia del patrocinio ducal y también de la propia institución colegial, se llevasen a cabo 
estas actuaciones de mejora y reforma del templo ${ }^{1}$. Como gran parte de los edificios religiosos del antiguo Reino de Sevilla, la parroquia mayor de Osuna quedó muy maltratada por el terremoto de Lisboa de 1755 , por lo que en los años siguientes se llevaron a cabo obras de reparación y reconstrucción de sus partes dañadas. A esto se unía la influencia europea de aires neoclásicos llegada en tiempos de Carlos III que traía consigo también la renovación estética de estas iglesias. Y uno de los empeños principales de muchas de las autoridades eclesiásticas de la época fue el de solar nuevamente y de manera mucho más decente y rica los edificios, como sucedió en la propia catedral hispalense y muchos templos diocesanos, como los casos de la prioral de El Puerto de Santa María, la parroquia de Santa Cruz de Teba y la propia iglesia mayor ursaonense ${ }^{2}$.

La colegial tuvo varias solerías. El pavimento primitivo fue colocado en el año 1534, tras la conclusión del nuevo templo y su erección como colegial. Este suelo era de ladrillo, y, en parte, fue renovado en 1665 por el maestro alarife Francisco Angulo ${ }^{3}$. No obstante, será en el último tercio de la centuria dieciochesca, cuando se idee reemplazar el antiguo solado latericio por otro marmóreo. El proceso se origina a partir de un mandato episcopal de 1769 centrado en la renovación del solado de la capilla mayor y la construcción de dos púlpitos, todo ello ejecutado entre los años 1773 y 1776 por los picapedreros estepeños Juan Antonio Blanco y Miguel Rejano respectivamente 4 . Pero si bien la historia de los púlpitos es conocida, no lo es la actuación del cantero Juan Antonio Blanco que labró las losas que cubrirían las gradas del presbiterio.

El cantero Juan Antonio Blanco era ya apreciado en Osuna. De una familia de origen asturiana, nació en Sevilla en 1715, formándose con su padre Miguel

${ }^{1}$ Sobre la historia y el arte de la colegial y este periodo en concreto se puede consultar RODRÍGUEZ-BUZÓN CALLE, Manuel: La colegiata de Osuna. Sevilla, 1982, pp. 26-29.

${ }^{2}$ CEÁN BERMÚDEZ, Juan Agustín: Descripción artística de la catedral de Sevilla. Sevilla, 1804, pp. 26-27; GÓMEZ DE TERREROS GUARDIOLA, Pedro: "Mediciones y presupuestos del siglo XVIII: la solería de la catedral de Sevilla", en Actas del tercer congreso de Historia de la construcción. Vol. 1. Madrid, 2000, pp. 417-424; y RECIO MIR, Álvaro: "Mentalidad suntuaria y ornato del templo: el mecenazgo del cardenal Delgado y Venegas, arzobispo de Sevilla, patriarca de las Indias y capellán de Carlos III", en El comportamiento de las catedrales españolas del Barroco a los Historicismos. Murcia, 2003, pp. 416-417. En el caso de la iglesia prioral de El Puerto de Santa María, consultar RECIO MIR, Álvaro: "La transformación neoclásica de la Prioral de El Puerto de Santa María (Cádiz): tabernáculo, presbiterio y coro", Laboratorio de Arte, 19, 2006, pp. 303-327; y sobre la parroquia de Santa Cruz de Teba ver BECERRA MARTÍN, Serafín; SAYAGO GARCÍA, Elvira y CUEVAS GÓNGORA, David: La iglesia parroquial de la Santa Cruz Real de Teba (1715-2015). Málaga, 2015, pp. 83-84.

${ }^{3}$ RODRÍGUEZ-BUZÓN CALLE, M.: La colegiata..., op. cit., p. 50.

${ }^{4}$ ROMERO TORRES, José Luis: "El escultor Fernando Ortiz, Osuna y las canteras barrocas", Cuadernos de los Amigos de los Museos de Osuna, 11, 2009, pp. 73-79. 
Blanco y trasladándose luego a la localidad de Estepa, de gran tradición lapidaria debido a las importantes canteras existentes en su término. Allí, en 1747 se desposó con la estepeña Catalina de Morales, hija del maestro mayor de obras de la villa, Nicolás Bautista de Morales. De este matrimonio, cuya casa y taller se encontraban en la confluencia de la calle Mesones con el Humilladero, nacerían siete hijos, entre ellos, los dos que heredarán el oficio, Nicolás y Ceferino, una vez muerto el patriarca el 26 de enero de $1792^{5}$. Obras de Juan, ayudado por sus dos hijos, fueron los mármoles enviados a la Fábrica de Tabaco, la solería de la Lonja de Sevilla y la piedra para la catedral de Cádiz, además de otras muchas obras para Estepa y sus alrededores. Y como dijimos en un principio también trabajará para Osuna, donde ya fue empleado en 1752 en la realización de las columnas, capiteles y pedestales del patio principal del colegio de la universidad de Osuna y en 1764 labró la importante portada del palacio del marqués de la Gomera $^{6}$. Por lo tanto, era una carta de presentación espléndida para que la colegial demandara sus servicios a la hora de plantear el embellecimiento del suelo de la capilla mayor.

Se iniciaron las obras el 27 de septiembre de 1773 y se invirtieron 413 losas blancas y 174 jornales con un costo de 472 reales; otros 400 reales por 280 losas blancas se le pagaron el 20 de noviembre de 1776; y finalmente 152 reales por 26 losas, incluido dos jornales y medio de un peón de albañil, se le abonaron el 12 de agosto de $1776^{7}$. Desafortunadamente, si bien el suelo blanco aún pervive, no así las gradas que originariamente se levantaban en todo el ancho del presbiterio y que eran de jaspe encarnado, las cuales fueron suplantadas en la restauración de Rafael Manzano, por un pódium y una escalera central de moderna factura (Figura 1).

Una vez solado el presbiterio faltaba el resto del templo, un empeño que se inició con otro mandato episcopal, concretamente del visitador don Agustín de Ayestarán y Landa, obispo de Botra y auxiliar de Sevilla, en el año 1790. En él se alertaba que "reconocido su piso y solado pésimo y que por la calidad mala de los ladrillos y su desunión se hallaba en estado de construir y formar un buen solado manda y ordena que el mayordomo de la fábrica sin pérdida de tiempo recurra al tribunal del señor provisor a fin de que nombre maestro inteligente que reconozca

${ }^{5}$ La biografía de Juan Antonio Blanco es recogida en DÍAZ FERNÁNDEZ, Ezequiel: "Notas de cantería ostipense: Juan Antonio Blanco, cantero", Laboratorio de Arte, 16, 2003, pp. 507-521.

${ }^{6}$ Sus trabajos en Osuna se pueden consultar en REINA REINA, José María: "La cantería en la Sierra Sur a lo largo del siglo XVIII", en Actas de las III Jornadas de Historia sobre la provincia de Sevilla. Sierra Sur. Sevilla, 2006, pp. 189-201.

7 Archivo General del Arzobispado de Sevilla (A.G.A.S.), sección Justicia, serie Ordinario-Fábrica, leg. 11307, Autos para la solería de la iglesia colegial de Osuna, año 1795, f. 177. 
el referido solado y necesidad del nuevo y forme un plan del modo y forma que se deba ejecutar el nuevo con la seguridad y consistencia posible evitando los defectos del antiguo y precediendo el correspondiente aprecio y cálculo del gasto que será necesario invertir en esta obra para que con este conocimiento se pueda emprender por partes y sin perjuicio de sus anuales y ordinarias obligaciones"8.

A partir del mismo se inició la maquinaria de tramitación ante el provisor episcopal, pero los escasos fondos con los que contaba la fábrica y el alto coste de las obras, hicieron que no se iniciase el proyecto, por lo que el mayordomo don Francisco José de Campos, el 15 de abril de 1795 solicitaba nuevamente al vicario general, don Juan Miguel Pérez Tafalla, que ante la situación que "en el día se halla dicha iglesia lo más indecente pues por donde quiera todos van tropezando con los pocos quebrados y desunidos ladrillos que le han quedado", rogaba iniciar las obras, teniendo localizado a un maestro inteligente que trabajaba en una cantera de Estepa, de donde se habían extraído las losas para la Casa de la Contratación de Sevilla, el cual podría comenzar de inmediato a labrar las baldosas blancas y negras con las que se ejecutaría dicha solería9. Para ello se pedía el nombramiento de un maestro que peritase el trabajo a realizar y estableciera las necesidades de material y jornales con los que se debía enfrentar la fábrica con arreglo a un plano que había sido ejecutado para tal efecto. El vicario general dio su consentimiento el 23 de abril, y dio mandato al vicario de la villa ducal para que nombrase al maestro especializado para tasar la obra. El elegido fue el alarife ursaonense Pedro Manuel Godoy, quien el 9 de mayo reconocía la solería de la iglesia colegial y, al día siguiente, el vicario don Juan de Aguilar redactaba un contundente informe, donde se argumentaba que, a pesar de ser una iglesia celebrada por ingenieros y maestros alarifes por "su corte, amplitud y solidez de su edificio", la solería se encontraba en un total abandono, con casi todos los ladrillos quebrados y levantados ${ }^{10}$. Asimismo se informó por parte de la fábrica ursaonense que, para hacer frente a las obras, podría venderse una casa de la antigua calle de Migolla, en la actualidad Luis de Molina, legada por el que fuera mayordomo de la fábrica don Martín Navarro ${ }^{11}$. Por ello, el vicario general pidió que se reconociera la vivienda por maestros alarifes, y el 23 de mayo los ursaonenses Vicente Alarcón y Francisco Ximénez fueron los elegidos ${ }^{12}$. Valorada la casa, el primero determinó que hacían falta algunos reparos, una nueva cuadra y puertas, y que se podría vender por 22.159 reales, y el segundo argumentó lo mismo,

${ }^{8}$ Ibidem, f. 1.

9 Ibid., f. 6.

${ }^{10}$ Ibid., ff. 8-9.

${ }^{11}$ Ibid., f. 10. Sobre la antigua calle de Migolla ver LEDESMA GÁMEZ, Francisco: Las murallas de Osuna. Osuna, 2003, p. 100.

12 A.G.A.S, sección Justicia, serie Ordinario-Fábrica, leg. 11307, Autos para la solería de la iglesia colegial de Osuna, año 1795, f. 10v. 
pero la tasó por algo más, 22.500 reales. Por lo tanto, con este dinero podría hacerse frente a parte del coste de la nueva solería, pidiendo ahora el mayordomo la licencia del vicario general para su venta. No obstante, en un auto del 2 de julio se le deniega, argumentándose que la fábrica tenía suficientes fondos como para poder ejecutar dicha obra ${ }^{13}$.

Esta negativa retrasó su comienzo, pues en la visita efectuada por don Tomás Macores, visitador general del Arzobispado, así lo expresó en un mandato fechado el 2 de diciembre de 1796. En él se aludía a que estaba "el solado tan malo e indecente de sus juntas con grave riesgo y perjuicio de los capitulares", que existía una verdadera necesidad de renovación, y además se especificaba que la fábrica, de sus rentas, solo podía destinar para gastos de ornamentos, obras y demás adventicios 16.000 reales anuales, con los que era difícil poder afrontar tal empresa. Por ello mandó al nuevo mayordomo de fábrica para que agilizase los trámites y que volviera a solicitar licencia para hacer el solado nuevo de piedra, en los términos que habían sido contratados entre el antiguo mayordomo Francisco Torres de Campo y el picapedrero estepeño Nicolás Blanco, quien ya tenía losas sacadas para tal efecto. Es, por lo tanto, la primera mención que se hace de uno de los artífices de la obra, un conocido para los canónigos, pues su padre había ejecutado las ya referidas losas de la capilla mayor.

Este mandato propició una nueva petición de la mayordomía a la vicaría general para que les permitiese vender la referida casa el 9 de agosto de 1797. El fiscal general pidió que el visitador volviese a la fábrica ursaonense y comprobase el estado de la solería y las rentas de la misma. Dicha visita se hizo el 22 de agosto del mismo año, y en ella don Tomás Macores ratificó el estado lamentable del suelo y examinó las rentas del templo. En ellas advierte que la fábrica contaba con 50.000 reales sobrantes en dineros y granos, tras haber pagado los salarios y las necesidades del culto, gracias a la buena cosecha del año anterior. Este remanente permitía poder pagar las losas que habían sido ya labradas por Nicolás Blanco, y así éstas no se perderían o venderían a otro comprador, lo cual sería muy gravoso para la fábrica. Además, los canónigos del templo colegial mostraron al visitador varios informes donde se exponía la fundada esperanza en que el patrono del templo, el duque de Osuna, pudiera socorrerles con alguna cantidad de dinero ${ }^{14}$. Ante este informe el fiscal general del Arzobispado autorizó el solado del templo

13 Ibidem, ff. 12-16.

${ }^{14}$ Una suposición ésta de patrocino ducal que nunca llegó. Sin lugar a dudas, los duques estaban financiando otras iglesias de su territorio, como las de Arahal, Olvera y La Puebla de Cazalla, de las que los Téllez Girón eran patronos. Además, eran los años en los que estaban también levantando la Alameda de Osuna en Madrid, e invertían sumas importantes en los retratos de Goya. Por ello, posiblemente la obra de la colegiata de Osuna no fuese nunca asistida, cuando ellos además ya tenían asignando parte de sus beneficios diezmales al mantenimiento de la iglesia mayor ursaonense. RECIO MIR, Álvaro: 
invirtiendo los fondos de la fábrica, y señalando que si hubiese necesidad se podría vender la referida casa ${ }^{15}$.

En los preparativos para iniciar la obra existía otro problema, el de las sepulturas que se disponían en la iglesia, un asunto delicadísimo, pues había que tener muy presente las prebendas de muchas de ellas y su ubicación tradicional ${ }^{16}$. Por ello, pidió licencia el representante de la fábrica colegial Manuel María Pérez al vicario, para que se llevase a cabo una adecuada reestructuración de las mismas, aludiendo a que en este templo solo prebendados y particulares con tumbas en propiedad hacían sus enterramientos. El 18 de junio accede y pide que se hiciese una gran bóveda con suficiente espacio para los enterramientos comunes del pueblo, además de blanquear y reparar la iglesia y hacer unas repisas para cuatro altares de las capillas de la Antigua y del Nacimiento. Por ello, el 22 de junio, el vicario de la villa nombra a Antonio Marín y Alonso Cabello, maestros alarifes ursaonenses, para que buscasen el lugar más apropiado para la bóveda y presupuestasen dicho trabajo, además de a los carpinteros Francisco y Cristóbal López para valorar las repisas aludidas. Al día siguiente, ambos albañiles coinciden en que la zona más adecuada para la ejecución del enterramiento era el trascoro, por estar cerca de la puerta del Sol, que, por el desnivel, permitía ventilar con ventanas la bóveda, la cual se podría labrar con piedra de la cantera local. El coste de vaciar el lugar, los materiales y los jornales venía a ser de 6.600 reales de vellón. Por su parte, los carpinteros, por la ejecución de los frontales de madera y repisas de altar, establecían el precio de 300 reales. El 3 de julio se dio licencia para hacer todas estas actuaciones previas al solado del templo ${ }^{17}$.

Es curioso que, en Osuna, en una fecha tan tardía, se esté pensando en construir en el templo una bóveda de estas características. Realmente, hasta esta misma centuria, una de las grandes funciones de las iglesias había sido la de enterrar a los muertos. Sin embargo, con la llegada de Carlos III y la Ilustración, se comienza a promover el enterramiento fuera del mismo, en un lugar a extramuros,

\footnotetext{
“'Pietate et constantia': el tabernáculo de la Parroquia de Olvera (Cádiz), el VI Duque de Osuna y el final de un modelo de mecenazgo", Laboratorio de Arte, 23, 2011, pp. 375-390.

15 A.G.A.S., sección Justicia, serie Ordinario-Fábrica, leg. 11307, Autos para la solería de la iglesia colegial de Osuna, año 1795, ff. 21-24.

${ }_{16}$ Sobre este asunto tan delicado, ver el ejemplo de otros templos como el del Salvador de Sevilla, que en el siglo XVII vivió una situación parecida. GÓMEZ PIÑOL, Emilio: La iglesia colegial del Salvador. Arte y sociedad en Sevilla (siglos XIII-XIX). Sevilla, 2000, pp. 308 y ss.

17 A.G.A.S., sección Justicia, serie Ordinario-Fábrica, leg. 11307, Autos para la solería de la iglesia colegial de Osuna, año 1795, ff. 39-40. La repisa o mesa de altar conservada es la del retablo de Nuestra Señora de la Antigua, un sencillo frontal de madera pintado con motivos jaspeados de tonalidades rojizas y marronáceas, además de presentar doradas sus cornisas y molduras. Asimismo, se dispone en el centro un emblema circular con una cruz inscrita entre rayos.
} 
concretamente a partir de la Real Cédula de Carlos III de 3 de abril de 1787. Por ello, que en 1797 se esté hablando de construir un enterramiento tradicional dentro del templo, es un dato a tener en cuenta de cómo una cosa era la teoría y otra la puesta en práctica de las ideas ilustradas, y cómo en la tradición de enterrar a los muertos no existía tanta conciencia al respecto y sí en otras actuaciones que estamos comentando ${ }^{18}$.

Lo cierto es que el 25 de septiembre se dio autorización para el solado del templo y la reubicación de las sepulturas en las capillas colaterales, mandando al vicario de la villa que tuviera como medio de financiación el caudal de la fábrica, cuya contabilidad habría de llevarse de manera controlada y rigurosa. El 11 de octubre siguiente, se pidió y se licenció quitar la crujía de hierro de la vía sacra que unía el presbiterio y el coro para poder así realizar mejor la obra ${ }^{19}$.

Será entonces, el 24 de noviembre de 1797, cuando la fábrica de la colegial contrate nuevamente con Nicolás y también con su hermano Ceferino Blanco la ejecución de las losas ${ }^{20}$. Ambos se comprometieron a labrar y poner todas las losas de mármol blanco y negro que se necesitasen para solar todo el edificio, siguiendo un diseño aprobado por la autoridad eclesiástica (Figura 2). Se estableció que en cada vara se dispondrían cuatro losas y su coste ascendería a 48 reales de vellón -6 por sacar y trasladar cada losa desde la cantera, 12 por su labrado y bruñido, y 2 por el asentado de las mismas-. Una disposición económica que debía estar en arreglo a las necesidades de los picapedreros, exponiendo además que habían recibido del mayordomo Pedro Bores 15.000 reales y que se ajustaría la cuenta en la Navidad de 1798, plazo previsto para la conclusión de los trabajos.

Por lo tanto, a partir de este momento se procede a la ejecución del proyecto inserto en este expediente, el cual muestra un damero de losas blancas y negras haciendo estas últimas un dibujo romboidal, muy utilizado por los Blanco en sus pavimentos, como se puede comprobar en varias iglesias de Estepa, como en el Carmen o en el camarín de los Remedios ${ }^{21}$. Las losas blancas se sacarían de las

18 ARIÉS, Philippe: El hombre ante la muerte. Madrid, 1983, pp. 398-431.

19 A.G.A.S., sección Justicia, serie Ordinario-Fábrica, leg. 11307, Autos para la solería de la iglesia colegial de Osuna, año 1795, ff. 26-29.

20 Ibidem, ff. 79-82v.

${ }^{21}$ Sobre la solería de El Carmen, obra de los Blanco de 1759, consultar RIVAS CARMONA, Jesús: "El Barroco en Estepa y el arte de la cantería: la portada del Carmen y su autor", en III Jornadas sobre Historia de Estepa. Estepa, 1998, pp. 407-447. La solería del camarín de los Remedios fue ejecutado por Juan Antonio Blanco entre 1781 y 1782. HERNÁNDEZ DÍAZ, José; SANCHO CORBACHO, Antonio y COLLANTES DE TERÁN, Francisco: Catálogo arqueológico y artístico de la provincia de Sevilla. Vol. 4. Sevilla, 1955, p. 60 . 
canteras de Moraleja y Juncarejo, a tres leguas de Osuna, y las negras de la Peña de Ardila y Perguelo ${ }^{22}$.

La evolución de las obras fue a buen ritmo, comenzando así el desmontaje del ladrillo y la llegada de parte de la solería que determinó diferentes actuaciones al respecto. Así, el 28 de mayo de 1798 se solicitaba el permiso a la vicaría general para vender la casa de la calle de Migolla, y hacer frente a los costes. Para ello los alarifes Antonio Marín y Alonso Cabello coinciden con la antigua tasación de 21.275 reales de vellón, por lo que se permitió su venta, pregonada en la plaza Mayor el 31 de mayo y subastada el 2 de junio, quedando rematada en don José Antúnez y Reina, canónigo de la colegial por el referido precio tasado. El 6 de julio el vicario pidió un informe sobre la estructura del edificio y su adecuación a las obras que se estaban llevando a cabo. El mayordomo respondió que la iglesia presentaba unos machos de piedra dura de Estepa y que las cornisas, las bóvedas y los muros perimetrales eran de arenisca de la cantera de Osuna; por ello, desde el terremoto de Lisboa -aquí aludido como el temblor de tierra general antiguo-, estas partes presentaban muchos "remiendos y parches", solicitándose el blanqueo general de las bóvedas y sus capillas, y dejando en piedra solo los pilares con sus columnas adosadas. El 19 de julio se permitió el blanqueo, que lo realizó Francisco Ximeno, siendo en este momento cuando desaparecieron gran parte de las pinturas murales, como las de la capilla de las Ánimas ejecutadas en 1731 o las hoy día recuperadas en parte de la capilla del Sagrario ${ }^{23}$. Una pérdida que también puede deberse a las nuevas ideas neoclásicas que tendían a mostrar la desnudez y pureza arquitectónica y eliminar cualquier rastro de barroquismo (Figura 3). Igualmente, en dos capillas existían sendas bóvedas de enterramientos que perjudicaban la buena disposición de las nuevas losas, por lo que se solicitaba, el 27 de agosto, que se hicieran nuevas bóvedas, petición que fue permitida por la vicaría general ${ }^{24}$.

La propia evolución de la empresa generó como es lógico cierto malestar en el desarrollo normal de la liturgia en el interior del templo. Por esta razón, el cabildo colegial se trasladó el 9 de diciembre de 1797 al convento de la Encarnación, explicando que lo hacían por la imposibilidad de guardar las Sagradas Formas, por no tener decente la pila bautismal y por el estado lamentable y de inseguridad del archivo $^{25}$. No obstante, la estrechez de los espacios que fueron

${ }^{22}$ A.G.A.S., sección Justicia, serie Ordinario-Fábrica, leg. 11307, Autos para la solería de la iglesia colegial de Osuna, año 1795, ff. 85-86.

${ }^{23}$ RODRÍGUEZ-BUZÓN CALLE, M.: La colegiata..., op. cit., p. 48.

${ }^{24}$ A.G.A.S., sección Justicia, serie Ordinario-Fábrica, leg. 11307, Autos para la solería de la iglesia colegial de Osuna, año 1795, f. 54.

${ }^{25}$ RODRÍGUEZ-BUZÓN CALLE, M.: La colegiata..., op. cit., p. 50; A.G.A.S., sección Justicia, serie Ordinario-Fábrica, leg. 11307, Autos para la solería de la iglesia Colegial de Osuna, año 1795, ff. 30-31. 
cedidos para el cabildo en el monasterio y la convivencia con la comunidad de monjas mercedarias, determinó que, a principios de 1798, los doctores y canónigos Francisco José del Campo, Alejandro Pérez y Mateo Guisado, pidieran permiso para trasladarse a otro templo de la localidad que no fuera la única iglesia auxiliar existente en la villa, la ermita de San Arcadio, demasiado pequeña para los servicios de la colegial y para atender a toda la feligresía. Rogaban trasladarse a la antigua iglesia jesuita, en el centro de la localidad y que pertenecía desde su expulsión a la Real Sociedad de Amigos del País, con capacidad y buena disposición para las funciones litúrgicas de la colegial. Finalmente, el 20 de febrero de 1798 se dio licencia para que durante las obras la colegial se trasladara a la referida iglesia de San Carlos el Real ${ }^{26}$.

Además, el 7 de agosto de 1798, el vicario autorizaba al mayordomo la ejecución de una nueva crujía de hierro para la vía sacra, cuyo coste se estableció en unos 5.000 reales, utilizándose el hierro de la antigua ${ }^{27}$. Para ello, el 20 de marzo anterior se contrató con Julián Montañés, herrero de la localidad, la hechura de una baranda de orden salomónico, con su media caña encima y debajo sus circunferencias con soleras, tal y como aparece en el diseño inserto en el contrato (Figura 4). Sin duda, una hechura sencilla de hierro que seguía los postulados tradicionales de la rejería local. Estaba compuesta por tramos delimitados por pilares con pirindola superior, enmarcando tres balaustres salomónicos, caracterizados por un ensanchamiento central calado y de desarrollo espiral, y soportado todo por carteras de roleos dispuestas en los entremos y en la parte central.

El 4 de diciembre de 1798 Nicolás y Ceferino rogaban al provisor y vicario general que atendiera la penosa situación económica por la que atravesaban debido a la obra ursaonense. Explicaban que debido a la tasación realizada de 48 reales la cuadra, el aumento de los salarios de los operarios y la demasía generada por el transporte de la piedra desde las canteras, habían tenido graves pérdidas, pues su valor era mucho mayor de lo tasado. Y ello lo ejemplificaban con el caso de la solería de la parroquia de Santa Cruz de Teba (Málaga), de mármol blanco y jaspe rojo, cuya cuadra había sido estimada en 20 reales más que la ursaonense, cuando incluso las canteras estaban más cercanas y el jaspe más dócil en su labrado, adelantando mucho más un operario en Teba que en Estepa ${ }^{28}$. Por todo ello, y con la comprensión de los propios eclesiásticos de la colegial, pedían que se aumentara el precio por cuadra para hacer rentable su trabajo.

${ }^{26}$ A.G.A.S., sección Justicia, serie Ordinario-Fábrica, leg. 11307, Autos para la solería de la iglesia colegial de Osuna, año 1795, f. 30-v.

27 Ibidem, f. 92-v.

${ }^{28}$ En la monografía sobre la parroquia de Santa Cruz de Teba se recoge la ejecución de esta obra entre 1795 y 1798 . BECERRA MARTÍN, S.; SAYAGO GARCÍA, E. y CUEVAS GÓNGORA, D.: La iglesia parroquial de la Santa Cruz..., op. cit., pp. 83-84. 
El vicario solicitó, el 5 de enero de 1799, un informe al canónigo más antiguo de la colegial, don Luis de Torres Montilla, para que verificase dicha situación. Éste explicaba que, a pesar de que la obra iba a buen ritmo y tenía solidez y firmeza conforme al diseño aprobado, los trabajos estaban en ese momento paralizados por ser invierno, con días lluviosos y cortos que no permitían trabajar en las canteras, y tampoco en el asiento de las losas por la humedad. Informaba también que la dieta de los operarios era muy elevada, tanto en la obra fina de la piedra como en la basta. Igualmente los eran sus portes desde la cantera, cuya saca de las negras distaba del templo cinco leguas y tres la saca de las blancas. Por todo ello, el verano pasado habían sufrido gran perjuicio en todas estas labores, pues solo se les pagaba 48 reales. Y ante la negativa a trabajar de los obreros por falta de remuneración, se decidió suspenderla en noviembre, a la espera de que mejorase el tiempo, acabasen las labores de la aceituna y hubiese más necesidad laboral en la población. Además, argumentaba también que el ajuste inicial fue equitativo, pero que, igual que había sucedido en otros lugares como Sevilla o Córdoba, el trabajo se había encarecido mucho, verificando que ambos maestros eran hombres honrados y buenos profesionales, pues los conocía de primera mano porque los contrató para labrar el retablo de Nuestra Señora de la Antigua de la misma colegial (Figura 5) ${ }^{29}$. Igualmente, certificó que ellos estaban ejecutando la solería de la parroquia de Santa Cruz de Teba por un valor mayor y con la piedra local aludida, tal y como le informó el cura local Pedro Felipe Hoyos. E incluso argumentaba que los hermanos Blanco habían tenido que gastar todo el grano que tenían almacenado en su casa para poder hacer frente a la obra ursaonense, expresando así que sería conveniente el aumento de 3 reales por losa, lo que vendrían a ser un aumento de 12 reales por cuadra, y con ello se hacía rentable su trabajo, sumando un total de 60 reales, doce menos que en Teba. Tras este informe y atendiendo a la petición de los hermanos Blanco, el vicario general determinó el 20 de febrero de 1799 que se le pagasen por cuadra 54 reales, reanudándose las obras a petición del mayordomo de la fábrica el 8 de marzo de dicho año ${ }^{30}$.

El 16 de mayo se presentaban las cuentas de las rejas de la vía sacra, las cuales sobrepasaron los 5.000 reales con los que se había presupuestado. Según carta de pago del mayordomo Pedro Bores, los gastos totales que había generado la nueva reja ascendían a 18.216 reales y medio, de los que se descontaba el valor del hierro de la anterior reja. Además, a esto se sumaba por el traslado del hierro a la colegial 120 reales, por los 34 agujeros abiertos para su colocación por el picapedrero

${ }^{29}$ Este retablo lo estudiamos en SANTOS MÁRQUEZ, Antonio J.: "El retablo de Nuestra Señora de la Antigua de la Colegiata de Osuna”, Cuadernos de los Amigos de los Museos de Osuna, 17, 2015, pp. 75-77.

30 A.G.A.S., sección Justicia, serie Ordinario-Fábrica, leg. 11307, Autos para la solería de la iglesia colegial de Osuna, año 1795, ff. 82-86. 
Hilario Bonilla otros 57 reales, por una tabla de Flandes para hacer los listones de las reglas y medidas para los hierros 26 reales, y por el pago al albañil y el peón para colocar la baranda otros 24 reales y medio. Dicha crujía de hierro hoy día tampoco se conserva in situ, pues fue desmontada en la restauración de Rafael Manzano al eliminar el coro del templo, siendo reutilizada en el cerramiento de varias capillas laterales (Figura 6) ${ }^{31}$.

La nueva solería siguió generando pérdidas debido al aumento de los jornales, lo que hizo a Ceferino suplicar nuevamente su revisión a través de un poder del 23 de junio de 1801 dado a Juan de Paula Hechón, procurador de los tribunales eclesiásticos. Así, éste presentó una demanda ante la autoridad eclesiástica rogando un cambio en el precio, pues a pesar del aumento de 1799, era imposible con 54 reales pagar la piedra y los jornales que suponía la cuadra de cuatro losas. Exponía que se habían solado hasta ese momento 500 varas y restaban otras 400 , por lo que se necesitaban para terminar la obra entre 24.000 y 30.000 reales más, y por ello pedía el aumento. Además, este precio podría mantenerse siempre que se buscasen canteras menos gravosas, habiéndose descubierto dos de mármol blanco en Écija y en Osuna, aunque lo que se venía cobrando en estas canteras por cuadra era entre 80 y 85 reales. Después de refrendar la petición, el vicario general autorizó la subida a 80 reales $^{32}$.

La obra a partir de ese momento fue a buen ritmo, solicitando los Blanco el 14 de septiembre de 1801 que se les abonase la elevada cifra de 200.000 reales de vellón. Sin duda, fue un intento de los picapedreros de recuperar todo lo perdido años atrás. Esta nueva petición la justificaban por el fallo originario en el cálculo del coste de la cuadra, por la inexistencia de concurso público en la adjudicación de la obra y por no ajustarse a las leyes de la época. Así solicitaban que, por el gran perjuicio que habían tenido por este trabajo, se les pagase la referida cantidad. Por ello se abren autos en la justicia episcopal, siendo en este momento, concretamente el 23 de septiembre, cuando fallece Ceferino, por lo que su hermano Nicolás y su suegro Alonso Ximénez de Aguilar como sus albaceas y representando a sus hijos y herederos Pablo y José María Blanco en el pleito, apoderaron para ello a Francisco de Paula Antón. Y como es habitual en este tipo de procesos judiciales, se solicitó información a diferentes testigos, todos refrendando la evolutiva pérdida de valor del trabajo de los hermanos Blanco por el encarecimiento de la saca de piedra de las canteras y por el acarreo y solado del templo. De hecho, argumentaban que le habían perdido a la cuadra de losas el doble de lo pagado, de ahí que se demandase dicha cuantía. Por tal causa, los Blanco se habían arruinado y habían valorado poner en subasta la obra, pero quedó desierta debido a la cuantía tan baja con la que se pagaba la cuadra de losas. Y ante esta situación,

\footnotetext{
31 Ibidem, ff. 92-95.
}

32 Ibid., ff. 101-109. 
el vicario general finalmente, el 16 de diciembre de 1802, determinó que se le abonasen a los Blanco todo lo adeudado.

A pesar de ello, esta deuda no será liquidada y la obra en primero de julio de 1803 aún no había sido concluida, por lo que el mayordomo Manuel María Pérez rogaba al maestro mayor de fábrica del arzobispado hispalense Fernando de Rosales que reconociera el trabajo y valorase la situación para acabar la obra; alertando éste y el alarife Alonso Cabello que era necesario buscar nuevas canteras, como la de Pruna, con el fin de agilizar la conclusión de las losas. Además, el vicario general apremió al referido mayordomo para que pagase a los Blanco y con ello poder terminar la solería. No obstante, la negativa a hacerlo por parte de los picapedreros, hizo que el mayordomo recurriera a otro lapidario vecino de Estepa, pero residente en Osuna, Nazario Tamarás para que la finalizase. El nuevo contrato firmado el 16 de septiembre de 1803 recogía los mismos términos del anterior, aunque se fijaba la cuantía de 77 reales y medio por cada vara de cuatro losas.

El 10 de junio de 1804, el maestro mayor Fernando de Rosales nuevamente inspeccionaba los trabajos por mandato del vicario general. Explicaba que la iglesia estaba solada prácticamente al completo, quedando solo el último tramo del templo, entre el trascoro y el muro de los pies, además de las capillas de San Pedro y la Virgen de los Reyes, valorando que para acabar la obra se necesitarían otros 11.000 reales aproximadamente en jornales y material, además de los 77 reales y medio por cuadra ${ }^{33}$.

Será el 20 de noviembre de dicho año, cuando Lucas José Mames, cura de la colegial y en nombre de la fábrica, exponga ante la autoridad eclesiástica que la solería del trascoro y de las referidas capillas había sido acabada por Nazario Tamarás y por el albañil Alonso Cabello. Por ello, el vicario general instaba al de la villa para que nombrase a personas inteligentes que inspeccionasen la obra. El vicario de Osuna, Francisco Aguilar, nombró al agrimensor Vicente Garrido para la tasación, declarando el 24 de dicho mes, que estaba bien ejecutada, y estableciendo que al lapidario se le debían 29.025 reales y al albañil 9.532 reales, montando este tramo final del solado 38.997 reales. Un dinero que la fábrica hizo efectivo como informó ese mismo día el referido vicario ${ }^{34}$.

Y con esta última noticia se acabó el largo proceso de más de ocho años que duró la obra de la solería de la colegiata de Osuna que desafortunadamente hoy día no se conserva en su integridad. En la restauración llevada a cabo en la década de 1960 y hasta su reapertura en 1976, el arquitecto Rafael Manzano levantó todo este solado y dispuso la ejecución de una nueva solería, donde se reaprovecharon algunas de estas antiguas losas, aunque el diseño originario no

\footnotetext{
${ }^{33}$ Ibidem, f. 282.

${ }^{34}$ Ibid., f. 286.
} 
se respetó ${ }^{35}$. Solo las capillas de la Concepción y algunas de las laterales conservan el diseño original de la solería, aunque gracias a las fotografías del templo anteriores a dicha reforma podemos actualmente contemplar cómo quedó finalmente la solería del templo mayor ursaonense (Figura 7).

Fecha de recepción: 28 de septiembre de 2016

Fecha de aceptación: 4 de enero de 2017

${ }^{35}$ Sobre la restauración de Manzano ver ROMERO TORRES, José Luis y MORENO DE SOTO, Pedro Jaime: "El patrimonio artístico: pérdida y dispersión", en Martínez Montañés y Osuna a comienzos del Barroco. Osuna, 2011, pp. 98-103. 


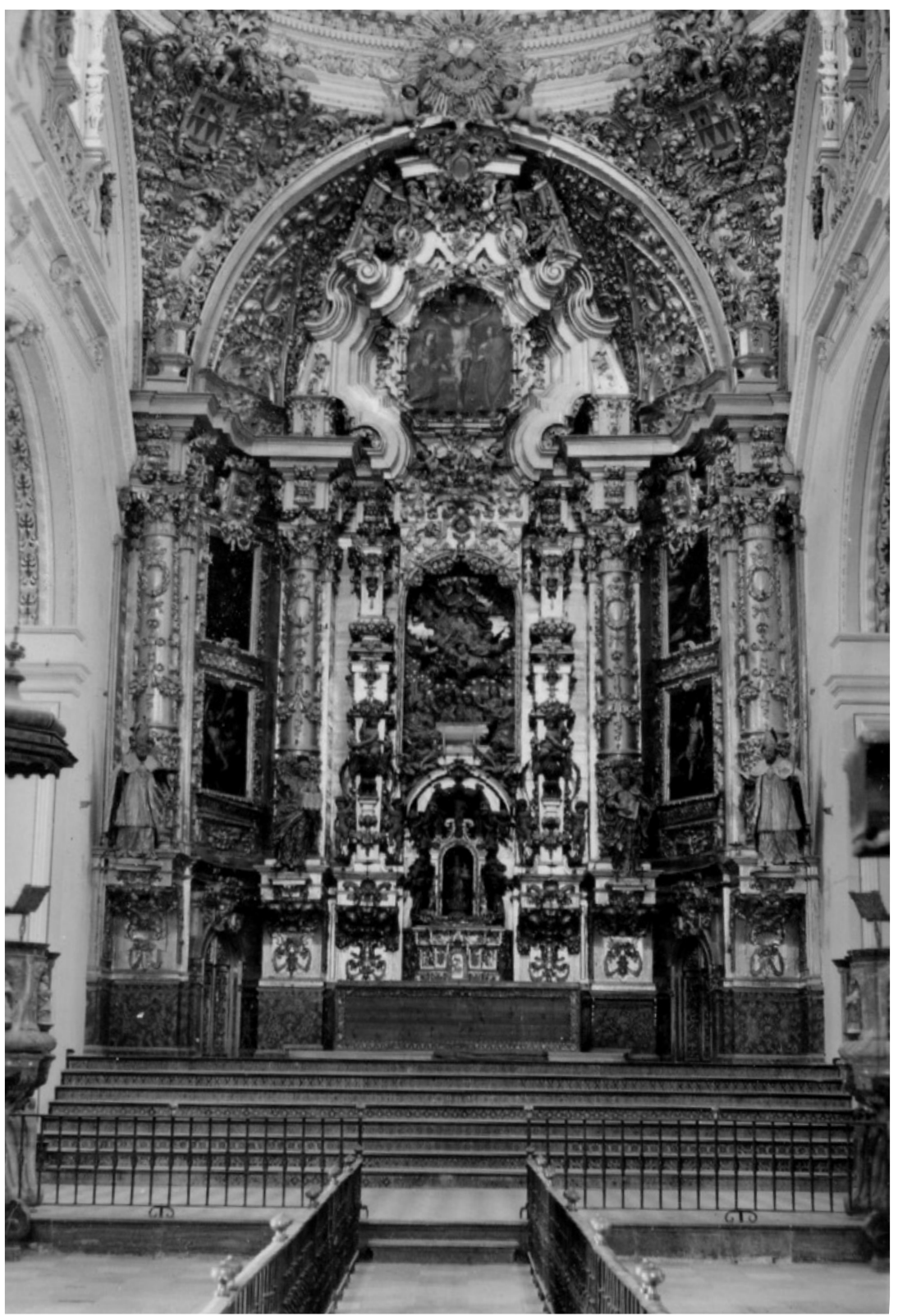

Figura 1. Juan Antonio Blanco, Gradas de la capilla mayor, 1773-1776, Colegiata de Osuna. Foto: Fototeca del Laboratorio de Arte, Universidad de Sevilla. 


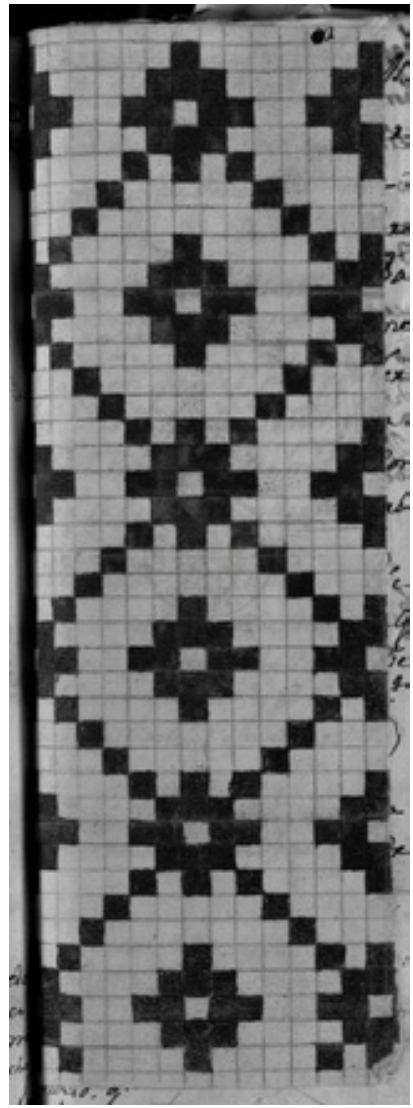

Figura 2. Nicolás y Ceferino Blanco, Diseño de la solería de la colegiata de Osuna, 1797. A.G.A.S., sección Justicia, serie Ordinario-Fábrica, leg. 11307, Autos para la solería de la iglesia colegial de Osuna, año 1795.

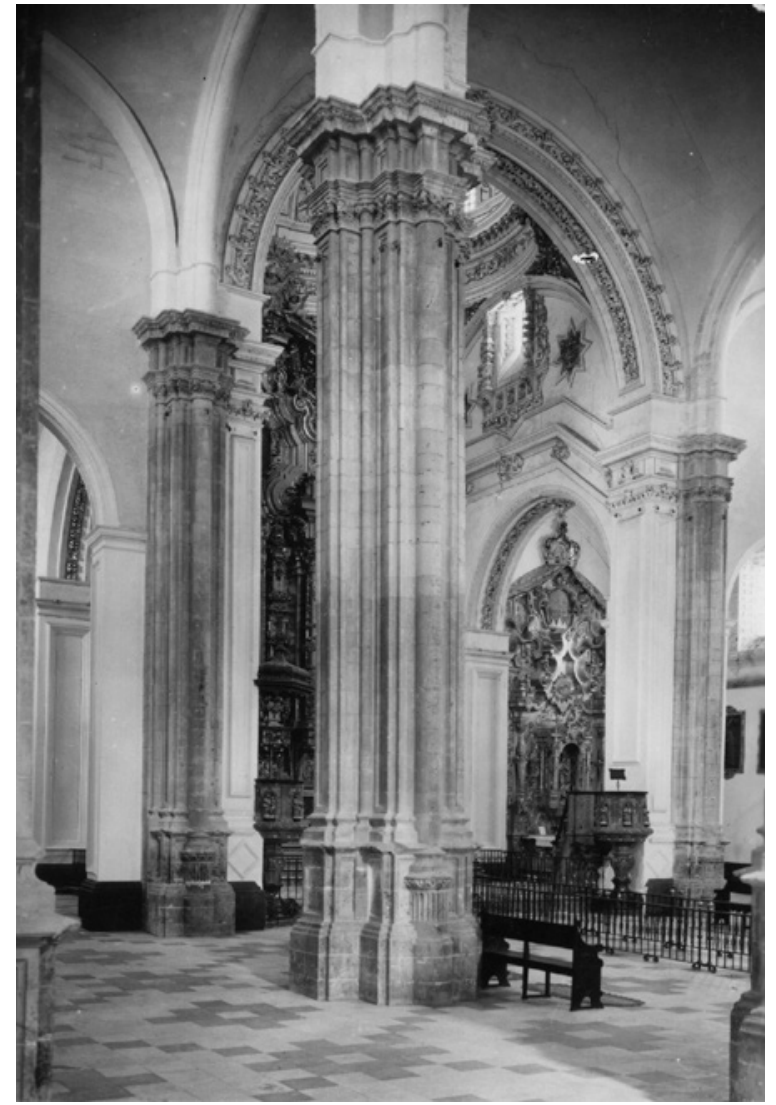

Figura 3. Vista interior de la colegiata de Osuna, donde se aprecian la solería, la vía sacra, los pilares de piedra y las bóvedas y muros blanqueados. Fotografía: Fototeca del Laboratorio de Arte, Universidad de Sevilla. 


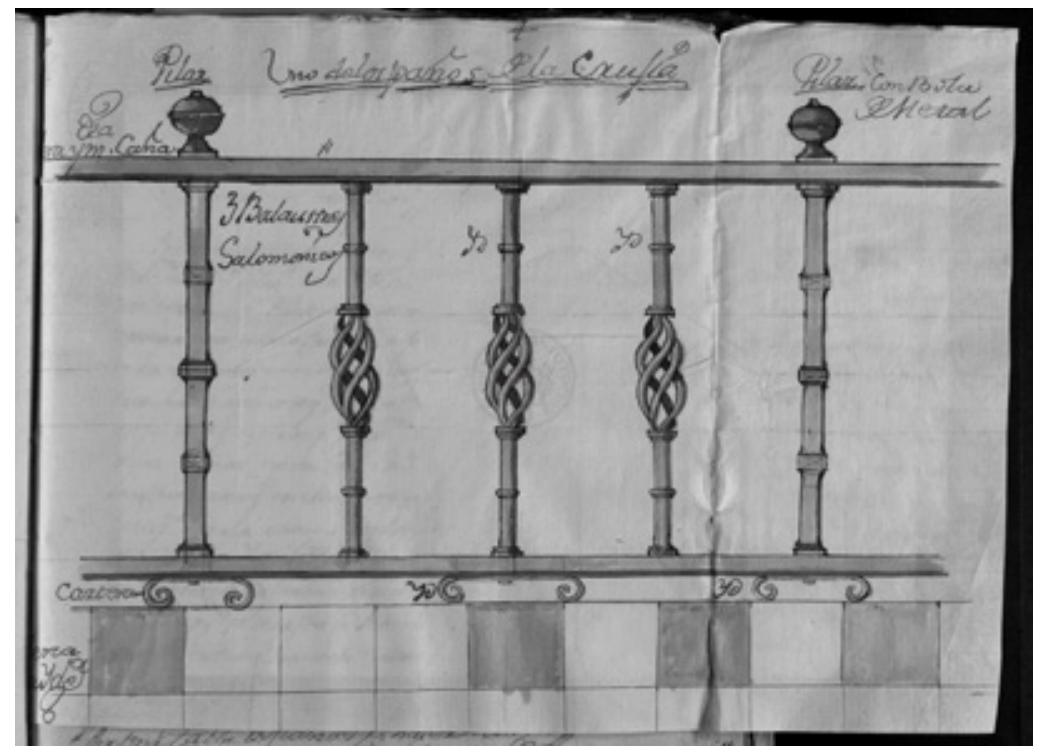

Figura 4. Julián Montañés, Diseño de la reja de la vía sacra, 1798. A.G.A.S., sección Justicia, serie Ordinario-Fábrica, leg. 11307, Autos para la solería de la iglesia colegial de Osuna, año 1795.

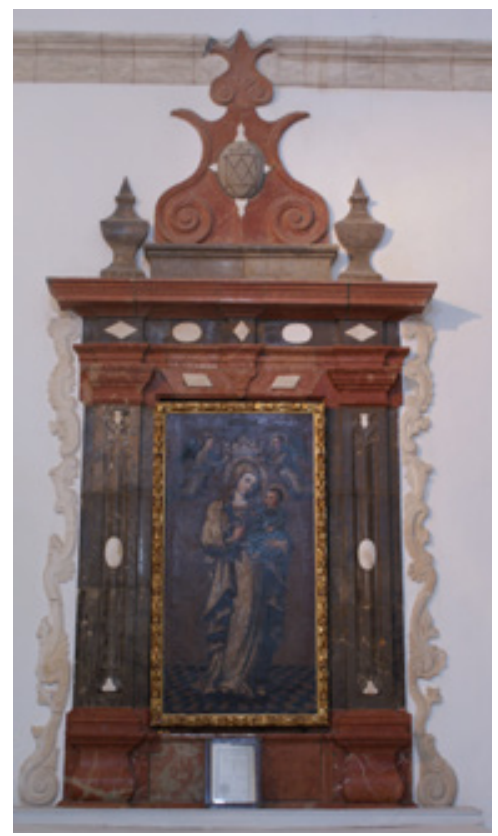

Figura 5. Nicolás y Ceferino Blanco, Retablo de Nuestra Señora de la Antigua, 1798, colegiata de Osuna.

Foto: Pedro Jaime Moreno de Soto. 


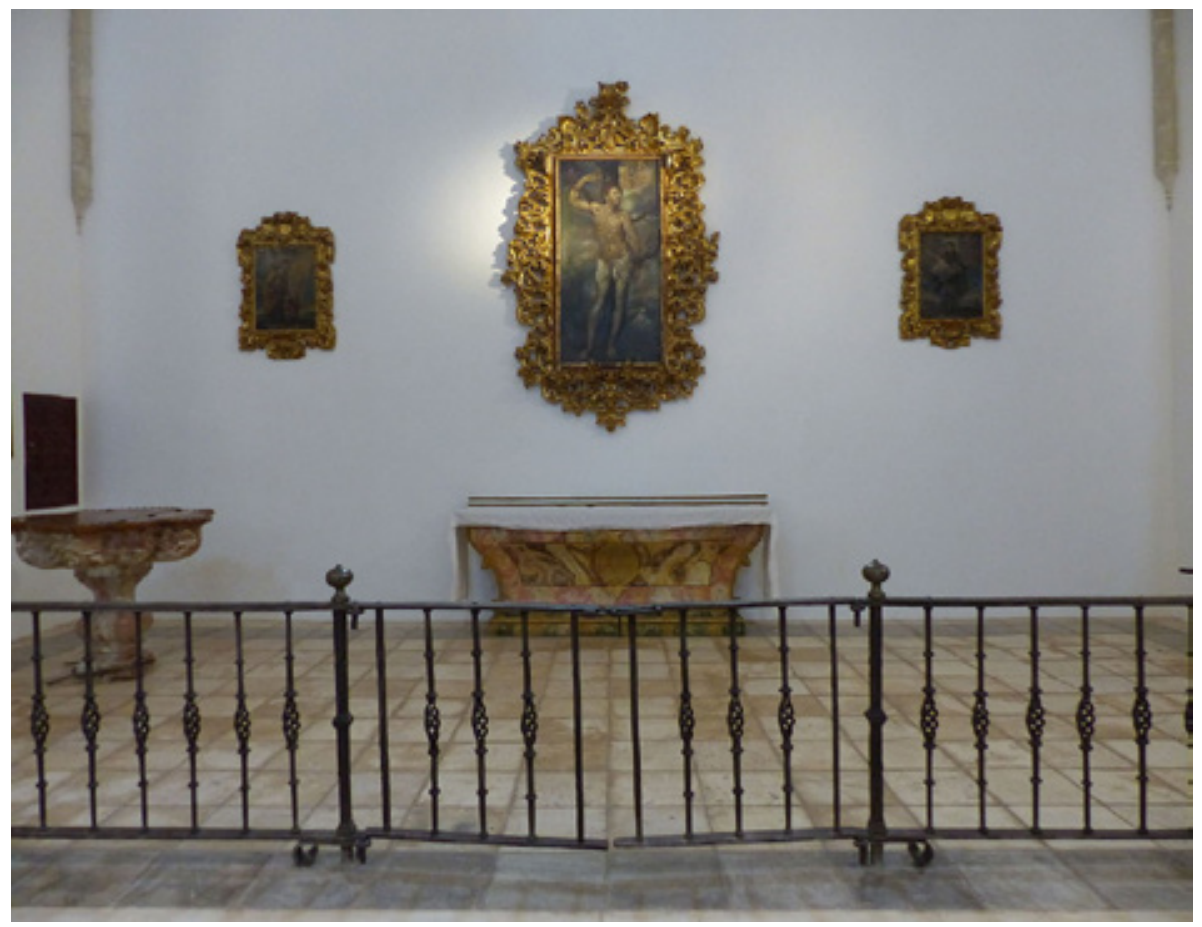

Figura 6. Julián Montañés, Reja de la capilla bautismal, antigua vía sacra, 1799, colegiata de Osuna. Foto: Antonio Santos. 


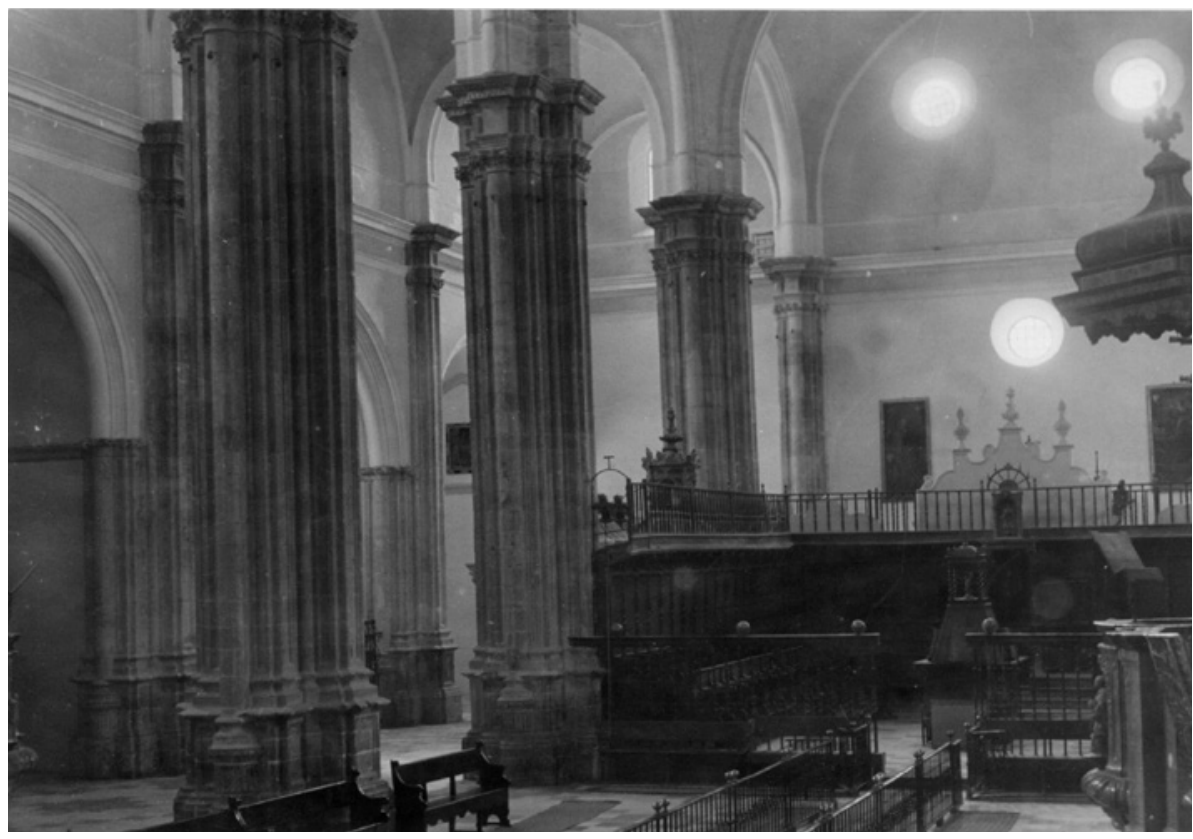

Figura 7. Vista interior de la colegiata de Osuna, donde se visualiza la solería, la vía sacra y el coro. Foto: Fototeca del Laboratorio de Arte, Universidad de Sevilla. 